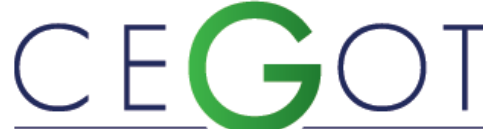

Centro de Estudos de Geografia e Ordenamento do Território
Pinheiro, Catarina de Almeida

Universidade do Minho, Departamento de Geografia / CEGOT - Centro

de Estudos de Geografia e Ordenamento do Território

4800-058, Guimarães, Portugal

catarina-pinheiro@mail.com

LARANJEIRA, MARIA MANUELA

Universidade do Minho, Departamento de Geografia / CECS - Centro de

Estudos em Comunicação e Sociedade

4800-058, Guimarães, Portugal

manuela.laranjeira@geografia.uminho.pt

BANDEIRA, MIGUEL

Universidade do Minho, Instituto de Ciências Sociais / CECS - Centro de

Estudos em Comunicação e Sociedade

4710-057 Braga, Portugal

sopasbandeira@gmail.com

\title{
Comportamento da temperatura de superfície em Braga e Guimarães no decorrer da onda de calor de julho de 2010
}

Land surface temperature in Braga and Guimarães during the heatwave of July 2010

Referência: Pinheiro, Catarina de Almeida; Laranjeira, Maria Manuela; Bandeira, Miguel (2020). Comportamento da temperatura de superfície em Braga e Guimarães no decorrer da onda de calor de julho de 2010. Revista de Geografia e Ordenamento do Território (GOT), n.o 20 (Dezembro). Centro de Estudos de Geografia e Ordenamento do Território, p. 254-279, dx.doi.org/10.17127/got/2020.20.011

\section{RESUMO}

As projeções climáticas apontam para um aumento da duração, frequência e intensidade das ondas de calor no Sul da Europa. Nos espaços urbanos a situação é ainda mais problemática, por causa do efeito da ilha de calor que exacerba as suas consequências. Sem embargo, pouco se sabe do comportamento das áreas urbanas perante esta anomalia climática, e particularmente como evolui a temperatura das diferentes superfícies (impermeáveis ou não) nestes dias de calor extremo. Neste cômputo, recorre-se a uma abordagem integrada da Deteção Remota (i.e., MODIS-Terra e MODIS-Aqua) com os Sistema de Informação Geográfica para estudar o comportamento do ambiente térmico superficial nos municípios de Braga e de Guimarães no decorrer da onda de calor de 23 a 30 de julho de 2010. Os resultados evidenciam que as variações no ambiente térmico ocorrem de modo gradual, coincidindo o pico da temperatura de superfície (Ts) com o dia com a temperatura do ar mais elevada. O processamento integrado das imagens MODIS patenteia bem que o centro urbano de Braga constitui uma área crítica em todos os horários, ao passo que Guimarães aparece relativamente mais fresco. Concluindo, os efeitos da onda de calor são assimétricos do ponto de vista temporal (i.e., nos diferentes horários do MODIS) e espacial, em função da cobertura do solo e da posição topográfica. Atendendo ao atual contexto de 
alterações climáticas esta informação revela-se indispensável na definição de políticas urbanas indutoras de um território ambiental e socialmente resiliente.

Palavras-chave: calor extremo; Deteção Remota; MODIS; temperatura de superfície; Normalized Difference Vegetation Index (NDVI); clima urbano; planeamento urbano.

\section{ABSTRACT}

Climate change projections point out to an increase in duration, frequency, and intensity of heat waves in Southern Europe. In urban spaces this situation is even more problematic, due to the urban heat island effect that exacerbates their consequences. However, little is known about the behavior of urban areas during this type of climatic anomaly, particularly how the temperature of different surfaces (impermeable or not) evolves in these days of extreme heat. Based on a Remote Sensing (i.e., MODIS-Terra and MODIS-Aqua) and Geographical Information Systems integrated approach we study the urban thermal environment of Braga and Guimarães municipalities during the heat wave of July 2010. The main results show that variations in the thermal environment occur gradually, coinciding the peak of land surface temperature (LST) with the highest air temperature. In conclusion, the heat wave effects are asymmetric in time (i.e., different MODIS times) and in space, depending on land cover and topographic position. Given the current climate change context, this information is critical to the development of urban policies that promote the environmental and social resilience of the territory.

Keywords: extreme heat; Remote Sensing; MODIS; land surface temperature; Normalized Difference Vegetation Index (NDVI); urban climate; urban planning.

\section{Introdução}

As projeções climáticas apontam para um aumento da temperatura média na Europa até 2100 (IPCC, 2018), particularmente no verão na região do Mediterrâneo (EEA, 2016a). A esta tendência soma-se ainda o aumento (IPCC, 2018; PNPOT, 2018): (i) do número de dias com temperatura muito elevada (i.e., temperaturas máximas superiores a $35^{\circ} \mathrm{C}$ ); (ii) das noites tropicais (i.e., temperaturas mínimas superiores a $20^{\circ} \mathrm{C}$ ); e, (iii) da frequência, duração e intensidade das ondas de calor (i.e., quando num intervalo de pelo menos 6 dias consecutivos, a temperatura máxima diária é superior em $5^{0} \mathrm{C}$ ao valor médio diário no período de referência; IPMA, 2010). Em concreto, desde 1880, na Europa Ocidental a duração média das ondas de calor no verão duplicou e a frequência dos dias muito quentes quase triplicou (EEA, 2012).

O acentuar do calor repercute-se diretamente no bem-estar da população (Bazaz et al., 2018). O calor extremo, designadamente os dias com temperaturas máximas superiores a $35^{\circ} \mathrm{C}$, temperaturas mínimas superiores a $20^{\circ} \mathrm{C}$ ou classificados como de onda de calor, 
potencia a mortalidade, particularmente nos grupos populacionais mais vulneráveis, entre os quais os idosos e as crianças, os doentes crónicos e os indivíduos socialmente mais isolados (Depietri et al., 2013). Note-se que "heat extremes are one of the most deadly and expensive climatic hazards in Europe" (EEA, 2012, p. 55). Estes efeitos podem estar diretamente relacionados com a exposição ao calor (insolação, desidratação, fadiga ou stress) ou dever-se ao agravamento de doenças preexistentes, nomeadamente as respiratórias e cardiovasculares, ou problemas renais (EEA, 2016b).

Nos espaços urbanos a situação é ainda mais problemática, dadas as especificidades intrínsecas à composição populacional (e.g., elevada densidade, população idosa), às atividades económicas (i.e., produção de calor antrópico) e à morfologia urbana que - por via do efeito de ilha de calor urbano - exacerbam as consequências dos eventos de calor extremo (Klock et al., 2012; Depietri et al., 2013). Neste sentido, os territórios mais urbanizados encontram-se profundamente vulneráveis quer no presente contexto de variabilidade climática, quer no cenário projetado de alterações climáticas (EEA, 2016a).

Dada a sua importância crescente, em termos populacionais e da economia, as áreas urbanas constituem o palco privilegiado para a implementação de medidas de mitigação e de adaptação ao calor extremo em resposta ao cenário de alterações climáticas projetado pois um território resiliente está inexoravelmente dependente de cidades resilientes. Neste contexto, "resilient' cities mean cities that are able to manage change by recovering from extreme weather events and transforming their infrastructure and the way they are organized to adapt to long-term climate changes" (EEA, 2017, p.2).

A pertinência da escala local no combate às alterações climáticas repercutiu-se na elaboração de Estratégias Municipais de Adaptação às Alterações Climáticas - alavancadas em Portugal no âmbito do projeto 'ClimAdaPT.Local', promovido pela Fundação da Faculdade de Ciências da Universidade de Lisboa (conjuntamente com a participação de onze entidades parceiras) e financiado pelo Programa AdaPT, com comparticipação do EEA Grants a $85 \%$ e do Fundo Português de Carbono a 15\% (APA, 2020).

A despeito do elevado número de estudos acerca do ambiente térmico, e muito particularmente sobre o fenómeno da ilha de calor urbano, pouco se sabe acerca do comportamento das áreas urbanas no transcurso das ondas de calor (Dousset et al., 2007; 
Retalis et al., 2010; Ward et al., 2016) e de como a temperatura das diferentes superfícies (impermeáveis ou não) evolui nestes dias com calor extremo continuado. A temperatura de superfície (Ts), captada pelos sensores dos satélites, não constitui uma medição física direta, mas uma modelização efetuada a partir do valor de radiância do topo da atmosfera. De acordo com diversos autores (e.g., Nichol, 2005; Retalis et al., 2010), existe uma forte correlação entre Ts e a temperatura do ar, pelo que esta informação pode ser utilizada para identificar as áreas mais críticas de acumulação do calor (Pinheiro e Laranjeira, 2016). Para mais, ao contrário dos registos pontuais da temperatura do ar sobre os quais é necessário efetuar interpolações, as imagens de satélite apresentam valores homogéneos para o seu grau de resolução espacial, cobertura temporal contínua e sincrónica, e não implicam custos monetários (e.g., MODIS, Landsat).

Com esta investigação procura-se colmatar uma lacuna na pesquisa da Climatologia Urbana, dando particular atenção à evolução diacrónica de Ts perante condições de calor extremo continuado, como sucede nos dias de verão classificados como onda de calor. Em específico, recorre-se a uma abordagem integrada da Deteção Remota com os Sistema de Informação Geográfica para descortinar o comportamento térmico superficial dos municípios de Braga e de Guimarães no decorrer da onda de calor de 23 a 30 de julho de 2010 (IPMA, 2010), ocorrida num dos meses mais secos e quentes do período de 1931 a 2020 (IPMA, 2020). Apesar de ter sido anteriormente investigada a relação entre Ts e o processo de urbanização (e.g., Pinheiro e Laranjeira, 2013; Pinheiro et al., 2016a,b), bem como a vulnerabilidade da população aos eventos de calor extremo (Pinheiro e Laranjeira, 2016), a variação espaciotemporal de Ts ao longo de uma onda de calor neste território carece ainda de análise.

Considerando que a eficácia das medidas de mitigação e de adaptação ao calor extremo depende da sua adequabilidade à realidade local (IPCC, 2018; Bazaz et al., 2018; Sun et al., 2019), almeja-se que: (i) este estudo empírico constitua mais um elemento de análise nas estratégias climáticas dos municípios de Braga e de Guimarães; e, (ii) a sua metodologia (dentro das limitações existentes e necessárias adaptações) seja replicada a outras realidades territoriais e/ou anomalias climáticas. Em verdade, procura-se contribuir para uma maior transferibilidade do conhecimento académico para a gestão territorial. 


\section{Procedimentos Metodológicos}

\section{1. Área de estudo}

Os municípios de Braga e de Guimarães localizam-se no Norte de Portugal (Figura 1), mais especificamente no setor noroeste, comumente designado como Minho. Ainda que adstritos, estes municípios integram NUTS III distintas, pertencendo Braga à do Cávado e Guimarães à do Ave. À semelhança de todo o Minho, o território em estudo exibe uma extensa área urbana de matriz difusa mas densa (Ribeiro, 1994), como atesta a classificação das freguesias bracarenses e vimaranenses, quase em exclusivo, como Área Predominantemente Urbana (APU) e Área Mediamente Urbana (AMU), pelo Instituto Nacional de Estatística (Figura 1). Não obstante o contexto territorial comum, estes municípios evidenciam uma estrutura urbana dissímil - sendo o núcleo central de Braga claramente mais denso e verticalizado do que o de Guimarães, onde a difusão continua a caracterizar o processo de urbanização.

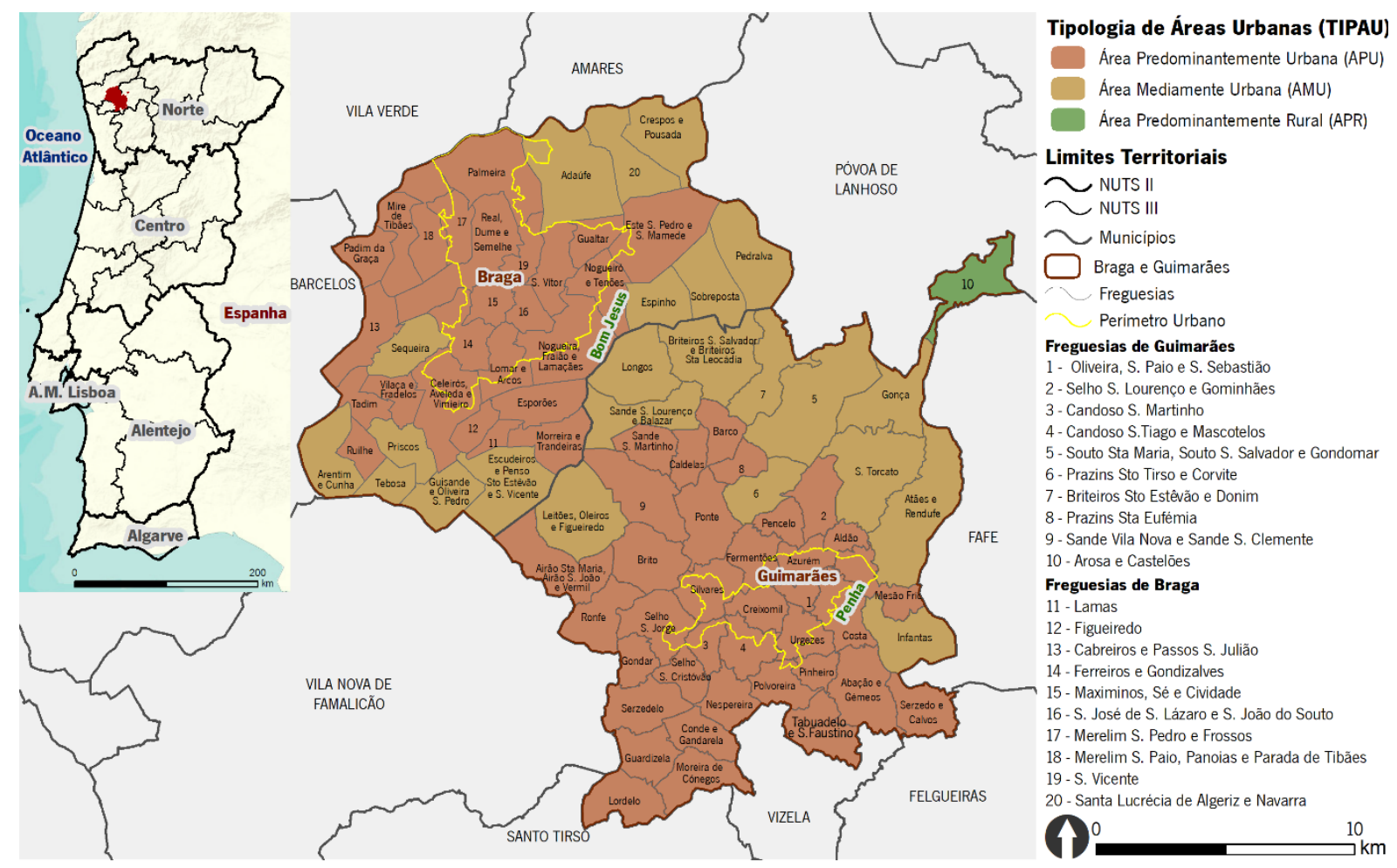

Figura 1 - Localização dos municípios de Braga e de Guimarães.

No contexto da divisão climática proposta por Daveau (1985), os municípios de Braga e de Guimarães inserem-se na região climática designada de 'fachada atlântica' (abaixo dos 600- 
700m), por ser ainda diretamente influenciada pelas massas de ar marítimas/atlânticas. Este tipo climático, relativamente chuvoso e caracterizado pela forte e persistente nebulosidade, apresenta alguns dias de forte calor e de frio sensível, que desaparecem sob a ação da brisa do mar no verão ou das massas de ar oceânico (Daveau, 1985).

De acordo com a Normal Climatológica de 1971-2000 da Estação Climatológica de Braga - a única no território em estudo - a média anual da precipitação acumulada é de $1465,7 \mathrm{~mm}$ (IPMA, 2019). Apesar de ocorrerem ao longo de todo o ano, os maiores quantitativos de precipitação registam-se entre o final do outono e o início da primavera (Figura 2). O mês com maior pluviosidade é janeiro $(192,7 \mathrm{~mm})$ e, por oposição, julho $(24,1 \mathrm{~mm})$ é o mês que regista os menores quantitativos. A temperatura do mês mais frio (janeiro) varia entre os $4,1^{\circ} \mathrm{C}$ (mínima média) e os $13,4^{\circ} \mathrm{C}$ (máxima média). Por sua vez, no mês mais quente (julho) a média das mínimas é de $14,3^{\circ} \mathrm{C}$ e a das máximas de $27,5^{\circ} \mathrm{C}$ (IPMA, 2019). No conjunto do ano registam-se em média 12 dias com temperaturas mínimas abaixo de $0^{\circ} \mathrm{C}$ e 90 dias com temperaturas máximas superiores a $25^{\circ} \mathrm{C}$, sendo que 30 dias ultrapassam os $30^{\circ} \mathrm{C}$ (IPMA, 2019).

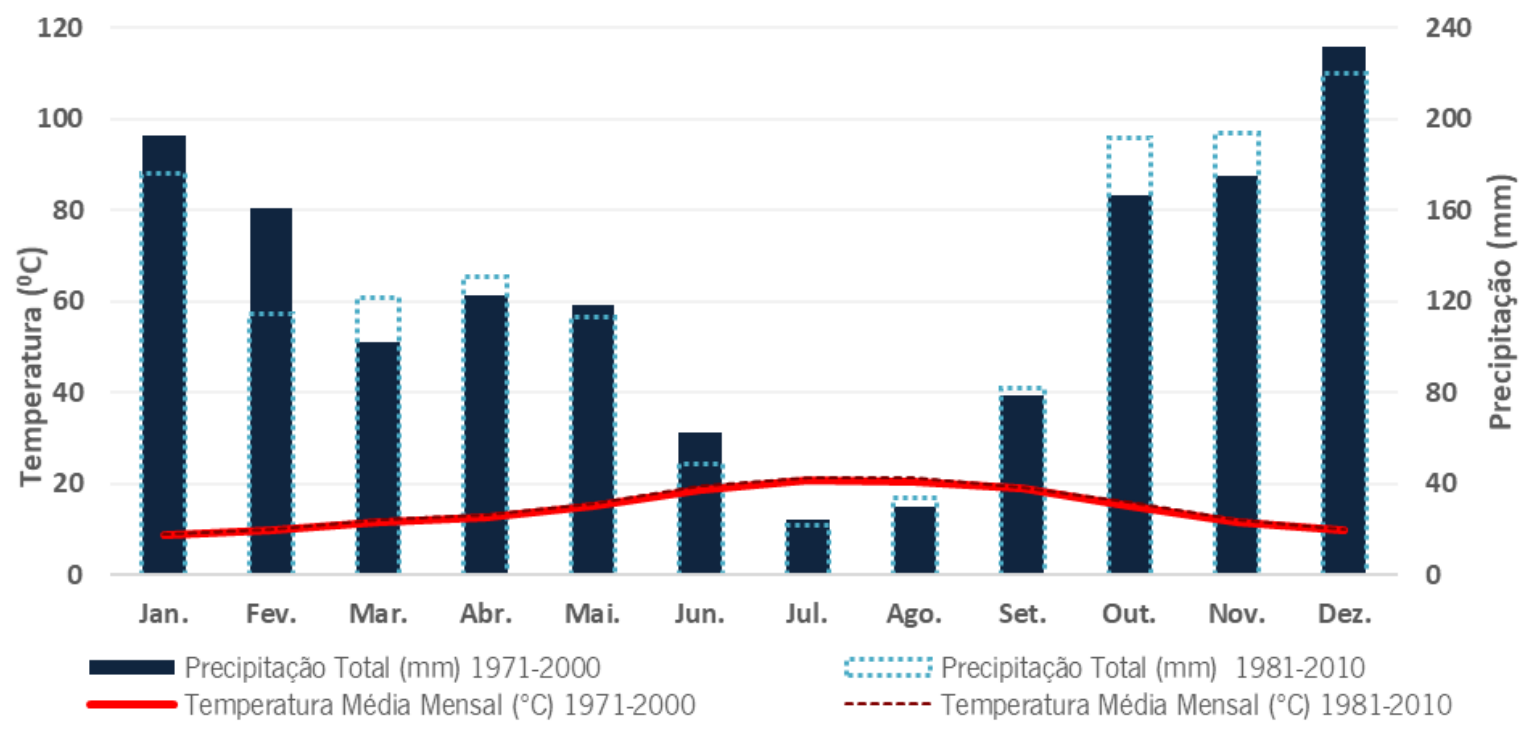

Figura 2 - Gráfico termopluviométrico da Estação Climatológica de Braga: perspetiva comparativa das Normais Climatológicas de 1971-2000 e 1981-2010.

Fonte: IPMA (2019).

Numa perspetiva comparativa entre as Normais Climatológicas de 1971-2000 e 1981-2010 (dados ainda provisórios; IPMA, 2019), sobressai o incremento dos valores da temperatura 
média nos meses de verão (entre $+0,5$ em julho e $+0,9$ em junho), ainda que este seja transversal a todos os meses do ano (e.g., $+0,1^{\circ} \mathrm{C}$ em fevereiro ou $+0,2^{\circ} \mathrm{C}$ em dezembro). $\mathrm{Na}$ precipitação, mais do que a redução nos quantitativos anuais $(-17,1 \mathrm{~mm})$, é modificação na repartição temporal que assume destaque (Figura 2).

Ao contexto de variabilidade climática observado (Figura 2) acresce o cenário de alterações climáticas, cujas projeções do IPCC (2018) apontam, no caso específico da Europa e do Mediterrâneo, para um aumento da temperatura do ar entre $0,6{ }^{\circ} \mathrm{C}$ e $4^{0} \mathrm{C}$ (no cenário RCP 4.5), bem como para o decréscimo da precipitação, porém com episódios mais frequentes de chuva intensa.

O cenário enunciado a nível global é corroborado à escala local pelas projeções disponibilizadas no Portal do Clima (em www.portaldoclima.pt) para a Estação Climatológica de Braga, designadamente no que se refere à subida dos valores de temperatura anual mínima e máxima até 2100 , com anomalias em torno de $+2^{\circ} \mathrm{C}$ no cenário RCP 4.5 e até $+6^{\circ} \mathrm{C}$ no cenário RCP 8.5 (Figura 3). Em relação à precipitação as projeções não evidenciam uma tendência tão nítida, uma vez que a incerteza associada é maior (Portal do Clima, 2015). Sem embargo, atente-se que as diminuições apontadas para a precipitação particularmente preocupantes entre o final da primavera e o início do outono (setembro) se vão agravando até 2100 (Figura 3).

\subsection{Dados}

Para estudar o ambiente térmico de Braga e de Guimarães no transcurso de uma onda de calor selecionou-se o episódio registado na Estação Climatológica de Braga entre os dias 23 e 30 de julho de 2010 (IPMA, 2010), tal como anteriormente se referiu. Em concreto, recorre-se ao sensor MODIS transportado pelos satélite Terra e Aqua, que em conjunto captam diariamente a temperatura de superfície (Ts) em quatro horários - i.e., 01:30, 10:30, 13:30 e 22:30, aproximadamente.

Nos produtos MOD11A1 (MODIS-Terra) e MYD11A1 (MODIS-Aqua) os valores de Ts são disponibilizados em conjunto com outra informação (e.g., emissividade, avaliação da qualidade dos pixels), numa resolução de cerca de $1 \mathrm{~km}$, após ter sido processada pela NASA em grelhas de $6 \mathrm{~km}$ tendo por base o algoritmo split-window. Esta informação é 
disponibilizada gratuitamente para todo o globo pelo Land Processes Distributed Active Archive Center (LPDAAC) da National Aeronautics and Space Administration (NASA).

O download das imagens MODIS foi efetuado a partir do Google Earth Engine Explorar (disponível em https://explorer.earthengine.google.com/). Esta plataforma agiliza a transferência das imagens (versão 6), além de que permite a sua extração no sistema de coordenadas WGS 84 (em vez da projeção Sinusoidal original) e no formato GeoTIFF (e não em HDF).

No conjunto dos oito dias da onda de calor extraíram-se 32 imagens, que não apresentam nebulosidade (excetuando-se apenas o horário da 01:30 do dia 25 de julho), nem a ausência de valores decorrentes de outras situações técnicas, como a baixa qualidade dos dados base. Seguindo os procedimentos descritos, efetuou-se ainda o download do Normalized Difference Vegetation Index (NDVI) que no conjunto do período em análise totalizam 16 imagens - 8 captadas pelo satélite Terra-MODIS às 10:30 e outras tantas pelo MODIS-Aqua às 13:30.

Adicionalmente, recorre-se ao ClimateEngine para extrair a informação climática decorrente do Climate Forecast System Reanalysis (CFSR), efetuado pelo National Centers for Environmental Prediction (NCEP), sob a égide da National Oceanic and Atmospheric Administration (NOAA). Disponibilizados numa grelha de $19,2 \mathrm{~km}$, os dados de reanálise climática apresentam uma resolução temporal diária que se estende de 1979 até ao dia corrente (NOAA, 2019). Deste modo, é possível efetuar um paralelo de Ts com diversos parâmetros climáticos, designadamente com: (i) a temperatura mínima, média e máxima do ar; (ii) a fração de humidade do solo a $5 \mathrm{~cm}$ e a $25 \mathrm{~cm}$; (iii) os fluxos de calor sensível e de calor latente; e, (iv) o potencial de evaporação. Importa notar que, o valor extraído para cada uma das variáveis anteriores corresponde à média dos dois municípios. 


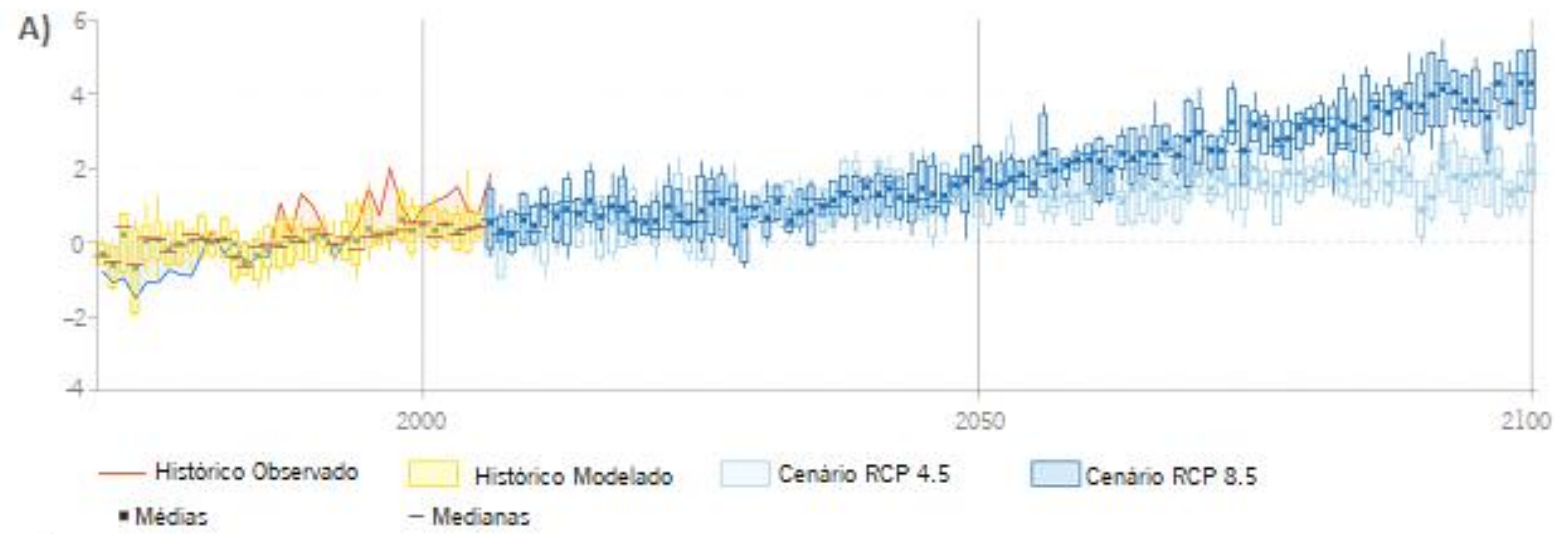

B)
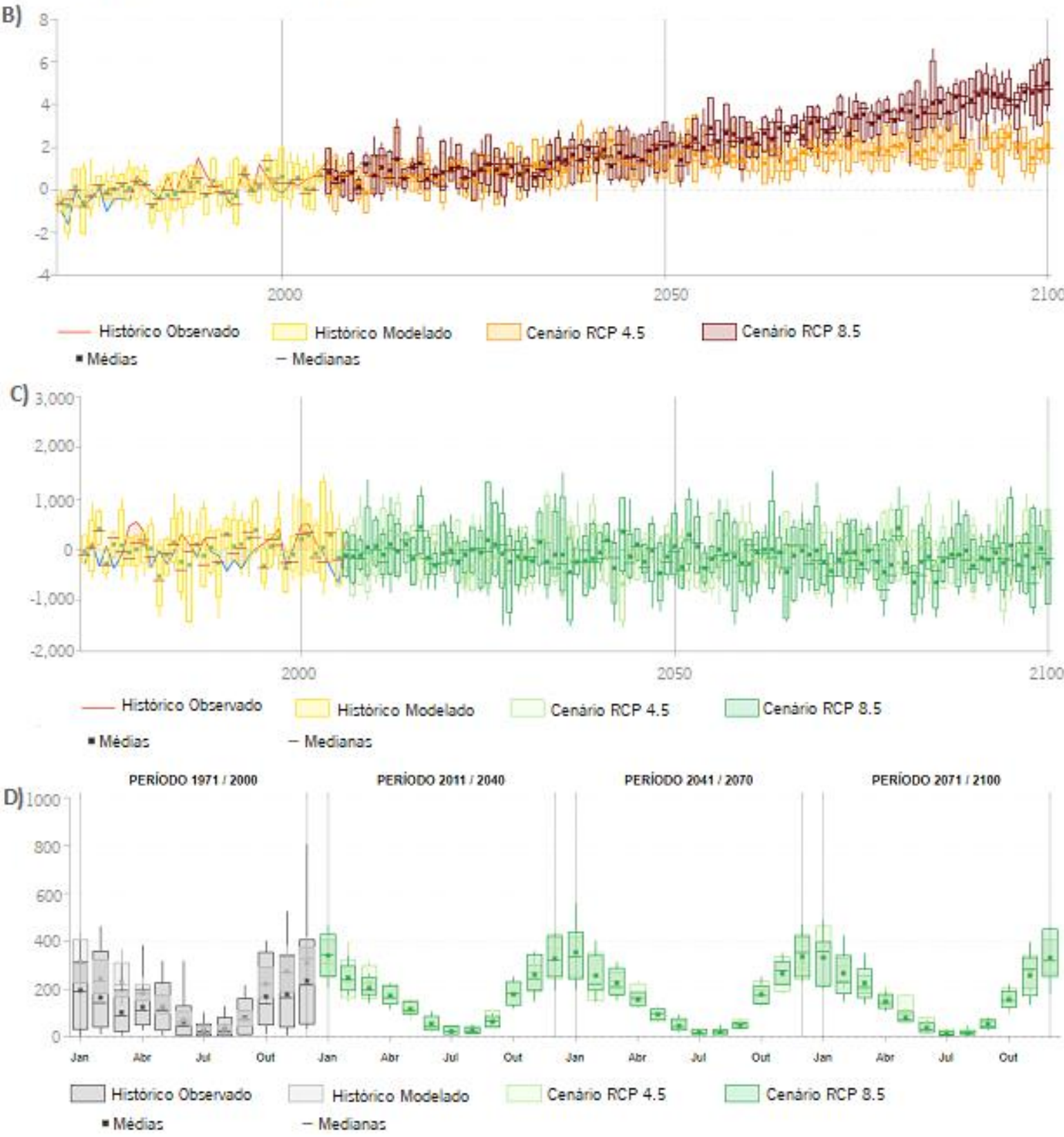

A) Anomalia da média anual da temperatura mínima; B) Anomalia da média anual da temperatura máxima; C) Anomalia da média anual da precipitação; D) Média mensal da precipitação.

Figura 3 - Projeções climáticas para a Estação Climatológica de Braga até 2100 Fonte: Portal do Clima (2015). 


\subsection{Processamento}

Após o download, as imagens MODIS foram sujeitas a uma fase de pré-processamento. Em específico, aplicou-se o fator de conversão aos produtos MOD11A1 e MYD11A, que no caso da temperatura corresponde à multiplicação dos valores por 0,02. A Ts obtida foi convertida de kelvin para graus celsius - i.e., aplicou-se a subtração de 273,15 . Os pixéis sem valor (por defeito, -9999) foram transformados em No Data (sem dados), para não interferirem com os cálculos estatísticos subsequentes. Em seguida, as imagens de Ts e do NDVI foram convertidas de WGS 84 para WGS_1984_UTM_ZONE_29N e recortadas para a dimensão territorial dos municípios de Braga e de Guimarães. Contudo, para evitar a perda de pixéis limítrofes definiu-se um buffer de $0,5 \mathrm{~km}$ para além dos limites administrativos destes municípios.

A análise do ambiente térmico, efetuada para o território dos municípios de Braga e de Guimarães em conjunto, considera invariavelmente cada horário do MODIS em separado. Importa notar que, os procedimentos computacionais doravante encetados assentam numa abordagem pixel-by-pixel - quer isto dizer, consideram cada um dos pixels da imagem de modo individual (Figura 4).

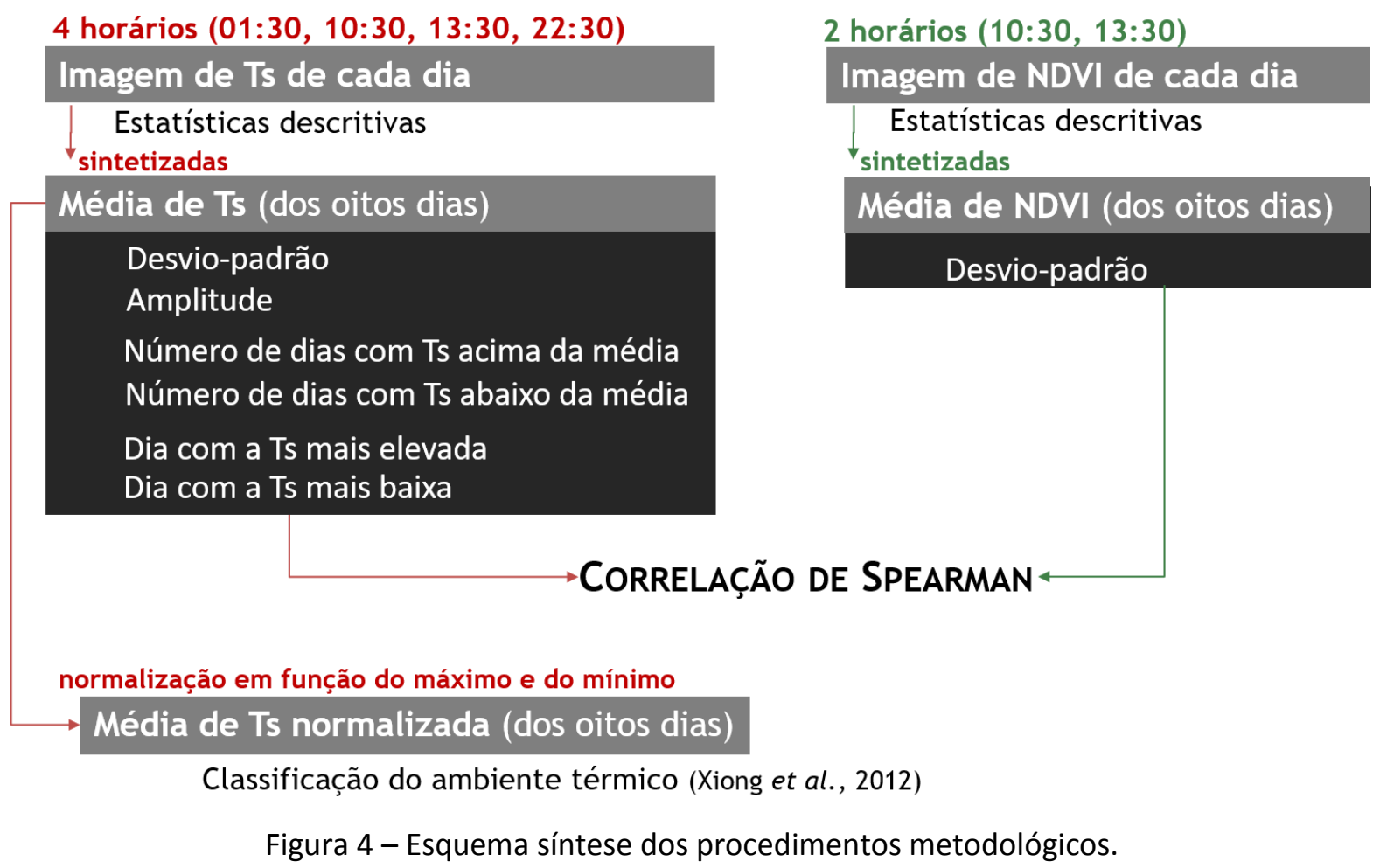


Primeiramente, com intuito de traçar a evolução de Ts nos 8 dias da onda de calor, derivaram-se as estatísticas descritivas pixel-by-pixel, especificamente o mínimo, máximo, média, desvio-padrão e a amplitude. De seguida, as 8 imagens de Ts referentes a cada horário do MODIS foram sintetizadas num único mapa, tendo como base o valor da média em cada pixel. A partir destas imagens calculou-se para cada pixel: (i) o desvio-padrão de Ts em relação à média; e, (ii) a amplitude dos valores, determinada pela diferença entre o valor máximo e o mínimo de Ts registada nos 8 dias em análise. Estes procedimentos foram executados no software ArcGIS, com recurso às opções Mean, Standard Deviation e Range da ferramenta Cell Statistics, disponível na extensão Spatial Analyst Tools. Vale ressalvar que, durante o processamento se optou por ignorar os pixéis sem dados (por estes terem uma distribuição espacial e temporal muito reduzida), - deste modo, o valor obtido decorre somente do observado nas imagens sem pixéis nulos.

Em paralelo, recorreu-se à imagem com a média de Ts de cada horário para precisar o número de dias em que no decorrer da onda de calor a temperatura se encontrou acima e abaixo da média em cada um dos pixéis, tirando partido das ferramentas Greater than Frequency e Less than Frequency, disponíveis na extensão do ArcGIS referida. Tendo ainda por base a imagem de Ts média de cada horário identificou-se para cada um dos pixéis o dia da onda de calor (correspondendo o dia um a 23 de julho e o oitavo dia a 30 de julho) em que a Ts foi mais elevada e o dia em que foi mais baixa, a partir das ferramentas Highest Position e Lowest Position, respetivamente. Estas ferramentas encontram-se agrupadas no ArcGIS na extensão Spatial Analyst Tools, sob a designação de Local, dado que efetuam os cálculos para cada um dos pixéis em função dos valores de todos os inputs adicionados que no presente caso correspondem aos valores de Ts em cada um dos dias do mês de julho classificados como onda de calor.

Relativamente ao NDVI, seguindo os procedimentos descritos anteriormente as imagens foram sintetizadas com base na média e no desvio-padrão, optando-se por realizar esta computação em separado para a informação proveniente do satélite Terra e do Aqua.

Os procedimentos descritos culminaram em nove layers de informação para cada horário do MODIS, nomeadamente (Figura 4): (i) média de Ts; (ii) amplitude de Ts; (iii) desvio-padrão 
de Ts; (iv) número de dias com Ts acima da média; (v) número de dias com Ts abaixo da média; (vi) dia da onda e calor com Ts mais elevada; (vii) dia da onda de calor com Ts mais baixa; (viii) média do NDVI; e, (ix) desvio-padrão do NDVI. Os valores referentes a cada pixel foram extraídos com base na grelha de 634 pontos, definidos pelo centroide de cada pixel da imagem MODIS. A relação de associação entre as nove variáveis foi determinada com recurso à correlação de Spearman (opção não-paramétrica da correlação de Pearson), calculada no software SPSS IBM Statistics.

Por último, procedeu-se à normalização dos valores médios de Ts de cada horário em função do máximo e mínimo de cada imagem, com a Ts normalizada a variar entre 0 e 1 . As imagens de Ts normalizada foram classificadas em função dos limiares propostos por Xiong et al. (2012), designadamente: 0 a 0,2 - área de frescura acentuada; 0,2 a 0,4 - área de frescura moderada; 0,4 a 0,6 - área mediana; 0,6 a 0,8 - área de calor moderado; e, 0,8 a 1 - área de calor acentuado. Esta padronização permite não só comparar diretamente os diferentes horários do MODIS, como também confrontar os dois municípios em estudo.

\section{Resultados e Discussão}

De acordo com o IPMA (2010), a onda de calor de 23 e 30 de julho de 2010 estendeu-se entre o Minho e o Alto Alentejo. Neste período, a temperatura do ar aumenta gradualmente desde o dia 23 até ao dia 27, e daí até ao dia 30 vai oscilando, registando-se neste último dia novo pico da temperatura (NOAA, 2019; Figura 5). Os dados de reanálise climática fornecidos pela NOAA (2019) encontram-se em concordância com os medidos pelo IPMA (2010), corroborando que o valor máximo da temperatura do ar em Braga - de $39,4^{\circ} \mathrm{C}$ - ocorre entre as $09 \mathrm{~h} 00$ do dia 27 e as 09 h00 do dia 28, que corresponde ao quinto/sexto dia da onda de calor.

No transcurso dos oito dias da onda de calor não se verifica a ocorrência de precipitação (NOAA, 2019). Esta esta situação conjugada com as temperaturas elevadas do ar traduz-se numa diminuição da humidade do solo (analisada a partir da fração de humidade), particularmente na camada mais superficial (nos $5 \mathrm{~cm}$ ) afetada mais rapidamente (Figura 6). 


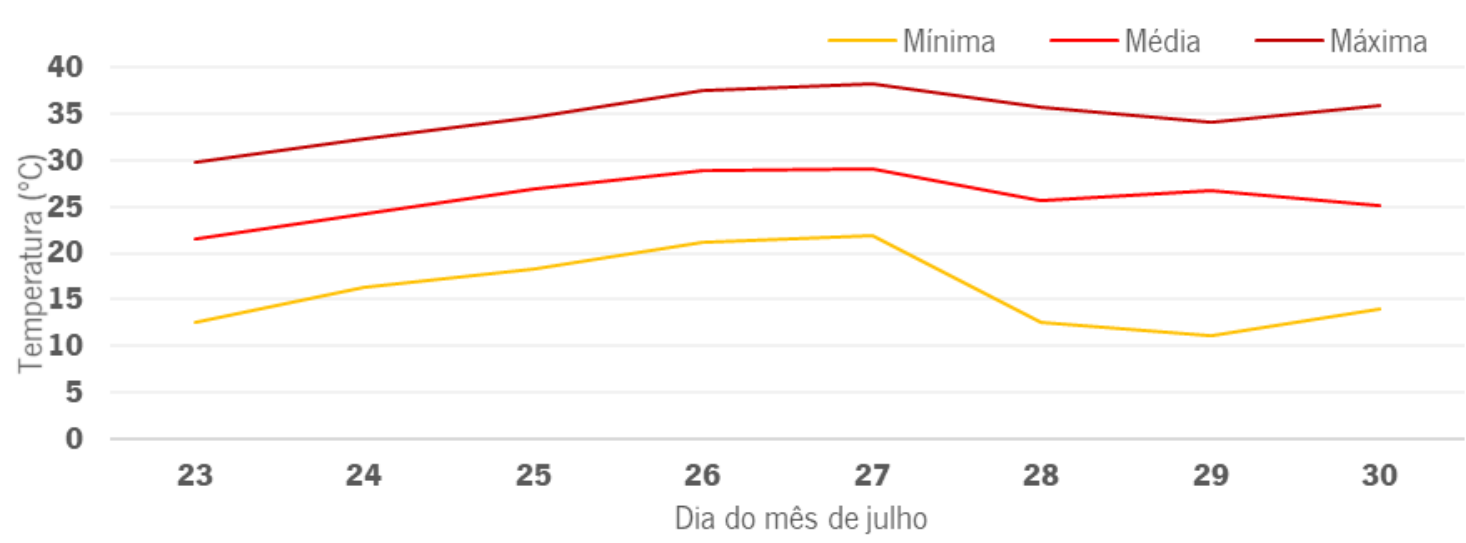

Figura 5 - Temperatura diária do $\operatorname{ar}\left({ }^{0} \mathrm{C}\right)$ em Braga e Guimarães no decorrer da onda de calor. Fonte: NOAA (2019).

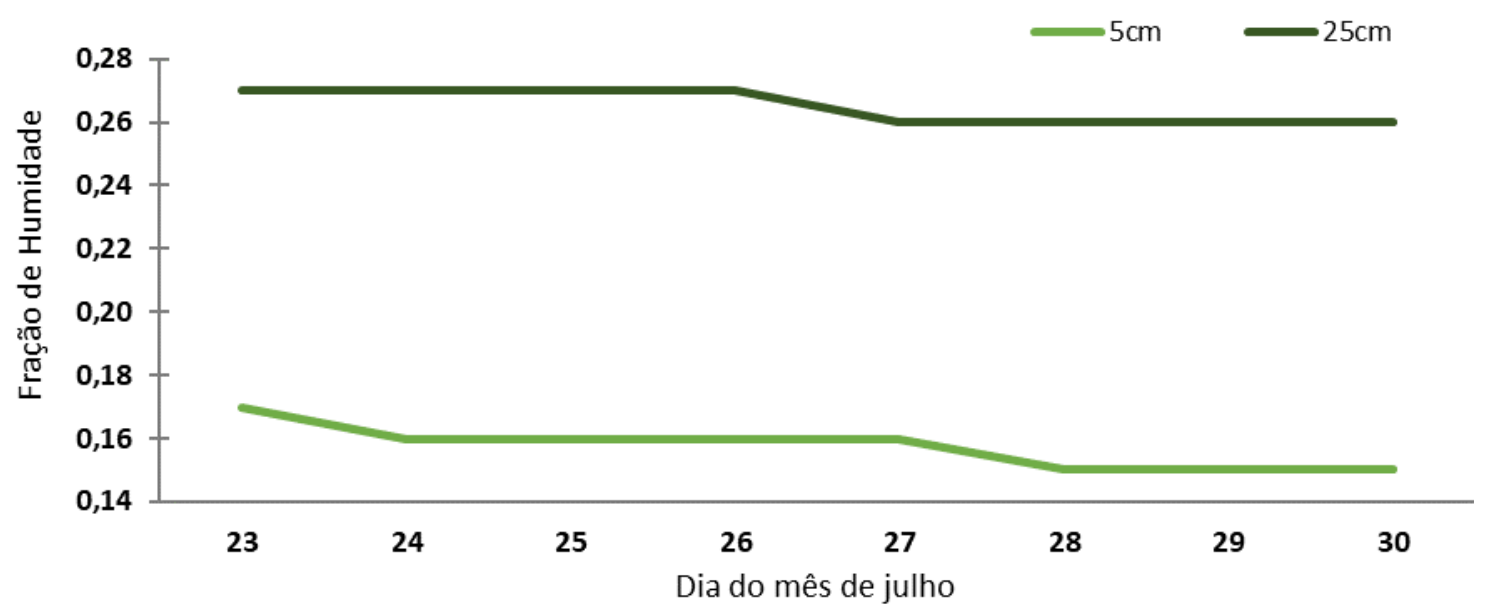

Figura 6 - Fração de humidade do solo, a $5 \mathrm{~cm}$ e a $25 \mathrm{~cm}$ de profundidade, em Braga e Guimarães no decorrer da onda de calor.

Fonte: NOAA (2019).

O NDVI, ao traduzir a quantidade e humidade da vegetação, permite relacionar Ts com as plantas - que desempenham um papel fundamental nas trocas de energia entre a superfície e a atmosfera. Em vista disso, este índice espectral tem sido amplamente utilizado como proxy das condições ecológicas do território (Zaitchik et al., 2006). Ressalvar que este índice apenas traduz a cobertura do solo, não informa acerca do seu uso. A título de exemplo, valores elevados de NDVI (superiores a 0,5) indicam a presença de vegetação arbórea densa que tanto pode ocorrer num povoamento florestal como num parque urbano. De igual modo, valores intermédios de NDVI (entre 0,3 e 0,5) indicam a presença de vegetação herbácea (ou arbustiva), mas não permitem distinguir um relvado num parque urbano de 
um ervado numa área agrícola. Apesar desta limitação, é possível a partir do NDVI inferir a ocupação do solo - correspondendo os valores baixos a áreas urbanas ou campos com solo nu e os valores elevados a áreas com vegetação arbórea e/ou densa (e.g., espaços verdes urbanos, povoamentos florestais), pelo que se torna possível relacionar as variações de Ts com a maior ou menor apropriação antrópica do território.

O valor médio do NDVI dos oitos dias classificados como onda de calor captado pelo sensor MODIS a bordo do satélite Terra por volta das 10:30 (Figura 7-A) e o captado pelo sensor MODIS transportado pelo satélite Aqua perto das 13:30 (Figura 7-B) são similares no que se refere à magnitude dos valores (i.e., mínimo e máximo) e ao padrão espacial (Figura 7), demonstrando que não existe perda de informação significativa na opção por um horário em detrimento do outro.
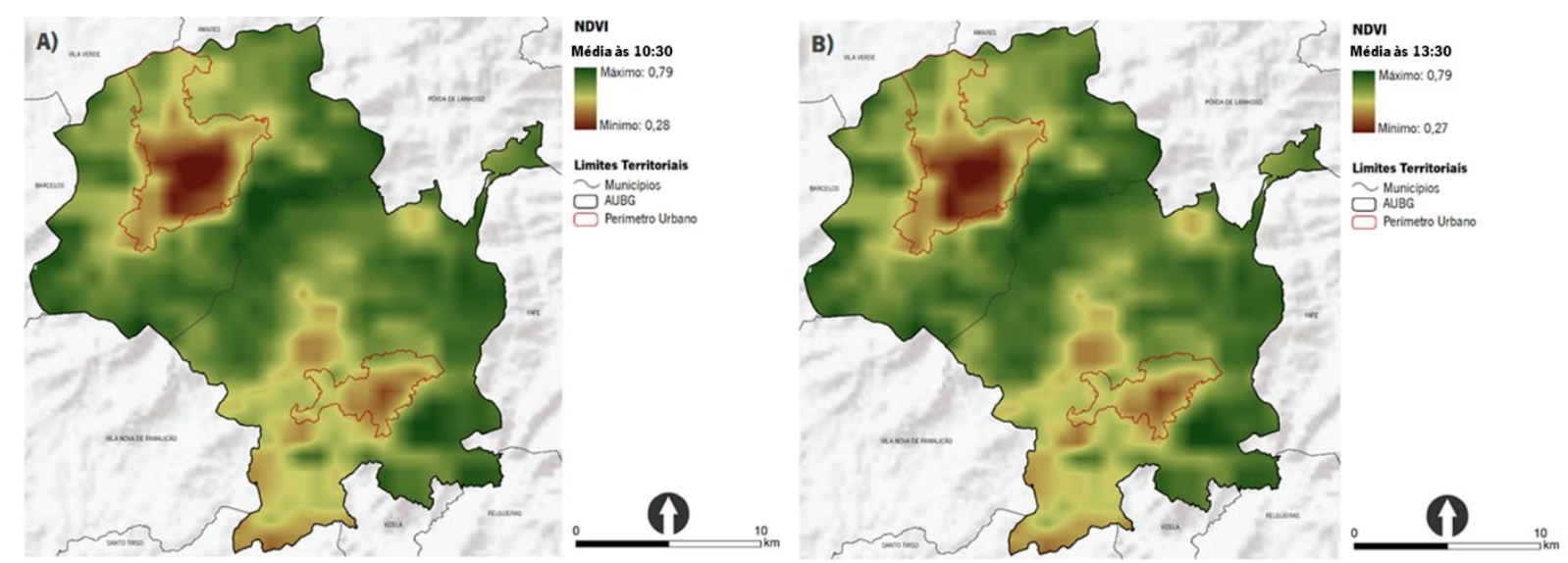

A) MODIS-Terra; B) MODIS-Aqua.

Figura 7 - Média do NDVI às 10:30 e 13:30 em Braga e Guimarães no decorrer da onda de calor.

Ademais, o NDVI coloca em evidência as dissimilaridades no padrão urbano entre os dois municípios, pois se em Braga sobressai a compacidade do núcleo central, limitado em grande medida pelo perímetro urbano, em Guimarães a urbanização difusa espraia-se amplamente no território.

\subsection{Evolução temporal}

A combinação dos arquivos MODIS Terra e Aqua permite traçar o perfil diacrónico de Ts (e, ao mesmo tempo sincrónico de Braga e de Guimarães) no transcurso da onda de calor em quatro momentos do dia - i.e., de madrugada (01:30), a meio da manhã (10:30), ao início da 
tarde (13:30) e ao início da noite (22:30). Estes horários, ainda que não traduzam os valores máximos ou mínimos diários, permitem estabelecer os ciclos de aquecimento e de arrefecimento das superfícies.

A análise dos valores de Ts nos quatro momentos do dia captados pelo MODIS demonstra que os valores mínimos, médios e máximos mais baixos ocorrem à 01:30 e 12 horas depois, às 13:30, regista-se a situação oposta. A meio da manhã (10:30) e ao início da noite (22:30) verificam-se situações intermédias, ainda que no primeiro caso as Ts sejam mais elevadas. No desenrolar da onda de calor as variações de Ts ocorrem de modo gradual nos quatro horários (Tabela 1).

Tabela 1 - Estatística descritivas pixel-by-pixel de Ts $\left({ }^{0} \mathrm{C}\right)$ nos quatro horários captados pelo MODIS em Braga e Guimarães no decorrer da onda de calor.

$\underline{01: 30}$

\begin{tabular}{ccccccc}
\hline $\mathbf{0 1 : 3 0}$ \\
\hline \multicolumn{6}{c}{ Dia } & \multicolumn{5}{c}{ Estatísticas Descritivas } \\
\hline $\begin{array}{c}\text { Mês de } \\
\text { julho }\end{array}$ & $\begin{array}{c}\text { Onda de } \\
\text { Calor }\end{array}$ & Mínima & Máxima & Média & Desviopadrão & Amplitude \\
\hline $\mathbf{2 3}$ & $\mathbf{1}$ & 10,53 & 15,39 & 12,96 & 0,73 & 4,86 \\
$\mathbf{2 4}$ & $\mathbf{2}$ & 12,23 & 17,45 & 14,87 & 1,16 & 5,22 \\
$\mathbf{2 5}$ & $\mathbf{3}$ & 12,03 & 19,77 & 16,22 & 1,64 & 7,74 \\
$\mathbf{2 6}$ & $\mathbf{4}$ & 17,87 & 24,15 & 21,42 & 1,34 & 6,28 \\
$\mathbf{2 7}$ & $\mathbf{5}$ & 17,91 & 24,89 & 22,19 & 1,63 & 6,98 \\
$\mathbf{2}$ & $\mathbf{6}$ & 17,69 & 24,71 & 21,19 & 1,49 & 7,02 \\
$\mathbf{2 9}$ & $\mathbf{7}$ & 16,71 & 21,89 & 18,75 & 0,72 & 5,18 \\
$\mathbf{3 0}$ & $\mathbf{8}$ & 15,89 & 21,75 & 18,57 & 1,24 & 5,86 \\
\hline
\end{tabular}

$13: 30$

\begin{tabular}{ccccccc}
\hline \multicolumn{3}{c}{ Dia } & \multicolumn{5}{c}{ Estatísticas Descritivas } \\
\hline $\begin{array}{c}\text { Mês de } \\
\text { julho }\end{array}$ & $\begin{array}{c}\text { Onda de } \\
\text { Calor }\end{array}$ & Mínima & Máxima & Média & Desviopadrão & Amplitude \\
\hline $\mathbf{2 3}$ & $\mathbf{1}$ & 32,07 & 43,83 & 37,90 & 2,10 & 11,76 \\
$\mathbf{2 4}$ & $\mathbf{2}$ & 32,79 & 41,49 & 36,38 & 1,56 & 8,7 \\
$\mathbf{2 5}$ & $\mathbf{3}$ & 37,27 & 48,29 & 42,13 & 1,98 & 11,02 \\
$\mathbf{2 6}$ & $\mathbf{4}$ & 36,67 & 42,97 & 39,14 & 1,28 & 6,3 \\
$\mathbf{2 7}$ & $\mathbf{5}$ & 38,07 & 49,05 & 42,64 & 1,86 & 10,98 \\
$\mathbf{2 8}$ & $\mathbf{6}$ & 34,85 & 43,57 & 38,55 & 1,45 & 8,72 \\
$\mathbf{2 9}$ & $\mathbf{7}$ & 35,03 & 44,99 & 39,10 & 1,87 & 9,96 \\
$\mathbf{3 0}$ & $\mathbf{8}$ & 35,05 & 45,75 & 40,10 & 1,70 & 10,7 \\
\hline
\end{tabular}

10:30

\begin{tabular}{ccccccc}
\hline \multicolumn{2}{c}{ Dia } & \multicolumn{5}{c}{ Estatísticas Descritivas } \\
\hline $\begin{array}{c}\text { Mês de } \\
\text { julho }\end{array}$ & $\begin{array}{c}\text { Onda de } \\
\text { Calor }\end{array}$ & Mínima & Máxima & Média & Desviopadrão & Amplitude \\
\hline $\mathbf{2 3}$ & $\mathbf{1}$ & 28,25 & 35,15 & 31,64 & 1,44 & 6,90 \\
$\mathbf{2 4}$ & $\mathbf{2}$ & 33,29 & 43,33 & 37,38 & 1,78 & 10,04 \\
$\mathbf{2 5}$ & $\mathbf{3}$ & 32,31 & 40,65 & 36,28 & 1,44 & 8,34 \\
$\mathbf{2 6}$ & $\mathbf{4}$ & 33,33 & 42,39 & 36,87 & 1,58 & 9,06 \\
$\mathbf{2 7}$ & $\mathbf{5}$ & 34,71 & 43,83 & 39,19 & 1,56 & 9,12 \\
$\mathbf{2 8}$ & $\mathbf{6}$ & 34,37 & 41,81 & 36,79 & 1,27 & 7,44 \\
$\mathbf{2 9}$ & $\mathbf{7}$ & 31,03 & 42,01 & 37,70 & 1,81 & 10,98 \\
$\mathbf{3 0}$ & $\mathbf{8}$ & 32,63 & 37,27 & 34,70 & 1,14 & 4,64 \\
\hline
\end{tabular}

\section{2:30}

\begin{tabular}{ccccccc}
\hline \multicolumn{3}{c}{ Dia } & \multicolumn{5}{c}{ Estatísticas Descritivas } \\
$\begin{array}{c}\text { Mês de } \\
\text { julho }\end{array}$ & $\begin{array}{c}\text { Cnda de } \\
\text { Calor }\end{array}$ & Mínima & Máxima & Média & Desvio-padrão & Amplitude \\
\hline $\mathbf{2 3}$ & $\mathbf{1}$ & 15,29 & 18,95 & 17,28 & 0,72 & 3,66 \\
$\mathbf{2 4}$ & $\mathbf{2}$ & 16,39 & 22,21 & 19,72 & 0,98 & 5,82 \\
$\mathbf{2 5}$ & $\mathbf{3}$ & 19,59 & 24,95 & 22,18 & 0,85 & 5,36 \\
$\mathbf{2 6}$ & $\mathbf{4}$ & 20,53 & 26,59 & 23,67 & 1,17 & 6,06 \\
$\mathbf{2 7}$ & $\mathbf{5}$ & 20,53 & 26,61 & 23,27 & 1,00 & 6,08 \\
$\mathbf{2 8}$ & $\mathbf{6}$ & 20,55 & 25,19 & 22,01 & 0,69 & 4,64 \\
$\mathbf{2 9}$ & $\mathbf{7}$ & 18,89 & 24,73 & 21,54 & 0,88 & 5,84 \\
$\mathbf{3 0}$ & $\mathbf{8}$ & 21,31 & 24,95 & 22,55 & 0,71 & 3,64 \\
\hline
\end{tabular}

O pico da carga térmica das superfícies coincide com o dia com a temperatura do ar mais elevada (c.f., Tabela 1 e Figura 5). De facto, Retalis et al. (2010) demonstraram que as Ts captadas pelos sensores MODIS têm forte correlação com a temperatura do ar medidas nas estações fixas (i.e., apresenta $u m \mathrm{R}^{2}$ de 0,65 ). Assim, considerando que a grande maioria das áreas urbanas não possui uma rede de estações meteorológicas suficiente para estudar as variações da temperatura à escala intraurbana, as imagens de satélite assumem-se como o meio mais eficiente para a sua compreensão. Em situações de calor extremo esta 
informação - ainda muito pouco utilizada (Dousset et al., 2007) - permite identificar os períodos (assim como os locais) mais críticos.

A análise estatística encetada, além de avaliar a linearidade da associação entre as diversas variáveis selecionadas (Figura 4), permite sintetizar a informação - tornando, em alguns casos, mais evidentes relações que do ponto de vista espacial não eram. Contudo, dada a dimensão e complexidade das tabelas decorrentes da Correlação de Spearman, realizadas para cada um dos horários do MODIS, optou-se por sintetizar numa única matriz os aspetos chave do comportamento térmico superficial do território dos municípios de Braga e de Guimarães no transcurso da onda de calor (Tabela 2).

Tabela 2 - Matriz síntese da correlação de Spearman dos aspetos chave do comportamento térmico superficial do território em Braga e Guimarães no decorrer da onda de calor de julho de 2010.

\begin{tabular}{|c|c|c|c|c|c|c|c|c|}
\hline Horário & Ts & NDVI & Ocupação do solo ${ }^{1}$ & $\begin{array}{c}\text { Amplitude e } \\
\text { desvio-padrão }^{2}\end{array}$ & $\begin{array}{c}\text { № dias acima } \\
\text { da média }\end{array}$ & $\begin{array}{c}\text { № dias abaixo } \\
\text { da média }\end{array}$ & $\begin{array}{l}\text { Dia com Ts } \\
\text { mais baixa }^{3}\end{array}$ & $\begin{array}{c}\text { Dia com Ts } \\
\text { mais } \\
\text { elevada }^{3}\end{array}$ \\
\hline \multirow{2}{*}{ 01:30 } & $\uparrow$ & $\uparrow$ & Vegetação & $\uparrow$ & $\downarrow$ & $\uparrow$ & $\downarrow$ & $\uparrow$ \\
\hline & $\downarrow$ & $\downarrow$ & Urbano/solo nu & $\downarrow$ & $\uparrow$ & $\downarrow$ & $\uparrow$ & $\downarrow$ \\
\hline \multirow{2}{*}{$10: 30$} & $\uparrow$ & $\downarrow$ & Urbano/solo nu & $\uparrow$ & $\downarrow$ & $\uparrow$ & $\downarrow$ & \multirow{2}{*}{$* * *$} \\
\hline & $\downarrow$ & $\uparrow$ & Vegetação & $\downarrow$ & $\uparrow$ & $\downarrow$ & $\uparrow$ & \\
\hline \multirow{2}{*}{$13: 30$} & $\uparrow$ & $\uparrow$ & Urbano/solo nu & $\uparrow$ & $\downarrow$ & $\uparrow$ & $\uparrow$ & $\downarrow$ \\
\hline & $\downarrow$ & $\uparrow$ & Vegetação & $\downarrow$ & $\uparrow$ & $\downarrow$ & $\downarrow$ & $\uparrow$ \\
\hline \multirow{2}{*}{$22: 30$} & $\uparrow$ & \multirow{2}{*}{$* * *$} & \multirow{2}{*}{$* * *$} & $\uparrow$ & \multirow{2}{*}{$* * *$} & \multirow{2}{*}{$* * *$} & \multirow{2}{*}{$* * *$} & $\downarrow$ \\
\hline & $\downarrow$ & & & $\downarrow$ & & & & $\uparrow$ \\
\hline
\end{tabular}

1. Ocupação do solo inferida a partir da interpretação dos valores de NDVI; 2 . A amplitude e o desvio-padrão traduzem as variações verificadas em Ts. Sentido de associação dado pelo valor da correlação de Spearman: $\uparrow$ positivo (i.e., aumento), $\downarrow$ negativo (i.e., diminuição), ${ }^{* * *}$ ausência de correlação significativa ( $p$-valor $\left.>0,05\right)$.

A relação negativa entre Ts e o NDVI amplamente estudada no espaço urbano (e.g., Weng et al., 2004, Lopes, 2003; Klock et al., 2012; Guo et al., 2015), apenas se verifica nos munícios de Braga e de Guimarães no período diurno (Tabela 2), sendo que o poder de explicação aumenta com o incremento da radiação solar. Com efeito, durante o dia, a presença de vegetação, ao favorecer os fluxos de calor latente, determina Ts mais baixas do que no solo nu seco ou nas superfícies impermeáveis. De madrugada, esta relação inverte-se, apresentando a Ts uma correlação positiva com o NDVI (Tabela 2), decorrente da maior 
inércia térmica das superfícies vegetadas. Deste modo, as áreas com vegetação mais densa ou arbórea, que em Braga e Guimarães correspondem maioritariamente aos topos do Bom Jesus e da Penha, apresentam à 01:30 Ts mais elevadas do que a área urbana ou do que os campos agrícolas. Às 22:30 a relação entre Ts e o NDVI encontra-se obliterada (i.e., $p$-valor da correlação superior a $>0,05)$, indiciando que a vegetação não desempenha um papel relevante na explicação da distribuição dos fluxos de calor, como sucede durante o dia (Tabela 2). Esta situação pode estar relacionada com o facto deste horário se encontrar próximo do thermal crossover (Nichol, 2005) - fenómeno que ocorre quando a assinatura do infravermelho de duas superfícies adjacentes se torna indistinguível (Retief et al., 2003).

A amplitude e o desvio-padrão de Ts traduzem a variação nos valores desta variável entre os dias 23 e 30 de julho de 2010. Em todos os horários a Ts média exibe uma correlação positiva com a variação no decorrer dos oito dias analisados (Tabela 2) - ou seja, Ts mais altas encontram-se associadas a maiores variações no decorrer dos oito dias. Contudo, tal não sucede sempre nas mesmas coberturas do solo, como se pode inferir pela leitura conjunta desta da informação com o NDVI (Tabela 2). Assim, no período diurno são os locais com baixo NDVI - entenda-se, os aglomerados urbanos (mais ou menos compactos) e os campos agrícolas com o solo exposto seco - que apresentam as variações mais acentuadas de Ts no decorrer da onda de calor. Durante a noite, a oscilação dos valores de Ts é mais evidente nas áreas com vegetação, conforme indica a correlação positiva entre o desviopadrão e a amplitude de Ts com o NDVI (Tabela 2). Às 22:30 esta constatação não advém da relação entre Ts e o NDVI (estatisticamente não significativa), mas sim da relação positiva entre as variações de Ts e a média do NDVI.

A média de Ts apresenta em todos os horários - com exceção das 22:30 - uma correlação negativa com o número de dias com Ts acima da média (logo, positiva com o número de dias com Ts abaixo da média; Tabela 2). Ao cruzar esta informação com a ocupação do solo inferida pelos valores de NDVI percebe-se que no período diurno são as áreas com vegetação que apresentam maior número de dias com Ts acima da média (Tabela 2). Todavia, de madrugada são as áreas urbanas e com solo nu (i.e., valores reduzidos de NDVI) que tendem a exibir o maior número de dias com Ts acima da média (Tabela 2). Uma vez mais, às 22:30 não se observam relações significativas (Tabela 2), pelo menos com base nos resultados estatísticos obtidos. Isto significa que os efeitos da onda de calor são mais 
notórios nas superfícies, que em cada horário, apresentam as Ts mais baixas (e não nas que se mantêm mais quentes, com menor número de dias com Ts acima da média).

Relativamente ao dia da onda de calor em que ocorre o valor mais elevado e o mais baixo de Ts, este varia significativamente em função da hora (Tabela 2). Na realidade, a relação inversa entre o dia da onda de calor que regista a Ts mais baixa e aquele em que ocorre a Ts mais elevada apenas se verifica nos horários de 01:30 e 13:30 (Tabela 3).

Tabela 3 - Registo do dia com Ts mais baixa e mais elevada no decorrer da onda de calor de julho de 2010, em função da ocupação do solo.

\begin{tabular}{|c|c|c|c|}
\hline Horário & Ocupação do solo ${ }^{1}$ & Dia com Ts mais baixa & Dia com Ts mais elevada \\
\hline \multirow{2}{*}{ 01:30 } & Vegetação & $y$ & $\pi$ \\
\hline & Urbano/solo nu & $\pi$ & ע \\
\hline \multirow{2}{*}{$10: 30$} & Vegetação & $\pi$ & \multirow{2}{*}{ Similar em todo o território*** } \\
\hline & Urbano/solo nu & ע & \\
\hline \multirow{2}{*}{$13: 30$} & Vegetação & $y$ & $\pi$ \\
\hline & Urbano/solo nu & $\pi$ & 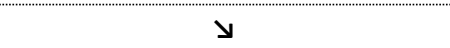 \\
\hline \multirow{2}{*}{ 22:30 } & Vegetação & \multirow{2}{*}{ imilar em todo o território*** } & $y$ \\
\hline & Urbano/solo nu & & $\pi$ \\
\hline
\end{tabular}

1. Ocupação do solo inferida a partir da interpretação dos valores de NDVI. Sentido de associação dado pelo valor da correlação de Spearman entre o NDVI (a partir do qual se infere a ocupação do solo) e o dia com a Ts mais alta e o dia com a Ts mais baixa: $\lambda$ positiva (i.e., tende a ocorrer mais tarde), $\searrow$ negativa (i.e., tende a ocorrer mais cedo), $* * *$ ausência de correlação significativa ( $p$-valor $>0,05)$.

Os efeitos da onda de calor nos municípios de Braga e de Guimarães são assimétricos do ponto de vista temporal - i.e., nos diferentes horários do MODIS - e espacial - decorrente da ocupação/uso do solo, ou de outros fatores, como a posição topográfica. A vegetação não aquece imediatamente no início da onda de calor (dado que a Ts mais baixa ocorre nos primeiros dias). Com efeito, o aumento de Ts vai sendo gradual, verificando-se o pico da temperatura mais tardiamente do que sucede nas áreas urbanas/solo nu (Tabela 3). Assim, entende-se que a vegetação resistirá ao aumento de Ts enquanto detém humidade - por via da evapotranspiração. Todavia, a perda de humidade do solo (vide Figura 6) acarreta uma diminuição da evapotranspiração, podendo mesmo esta, nos casos mais severos, cessar. Em consequência, os fluxos de calor latente vão enfraquecendo, ao passo que os fluxos de calor sensível assumem maior destaque. Na área de estudo esta situação é particularmente 
evidente após o pico da carga térmica (bem como da temperatura do ar e do potencial de evaporação) verificado no dia 27 de julho de 2010, o quinto dia da onda de calor (Figura 8). Em vista disso, os valores baixos de Ts verificados nos dias iniciais não voltam a figurar (Tabela 2 e Tabela 3).

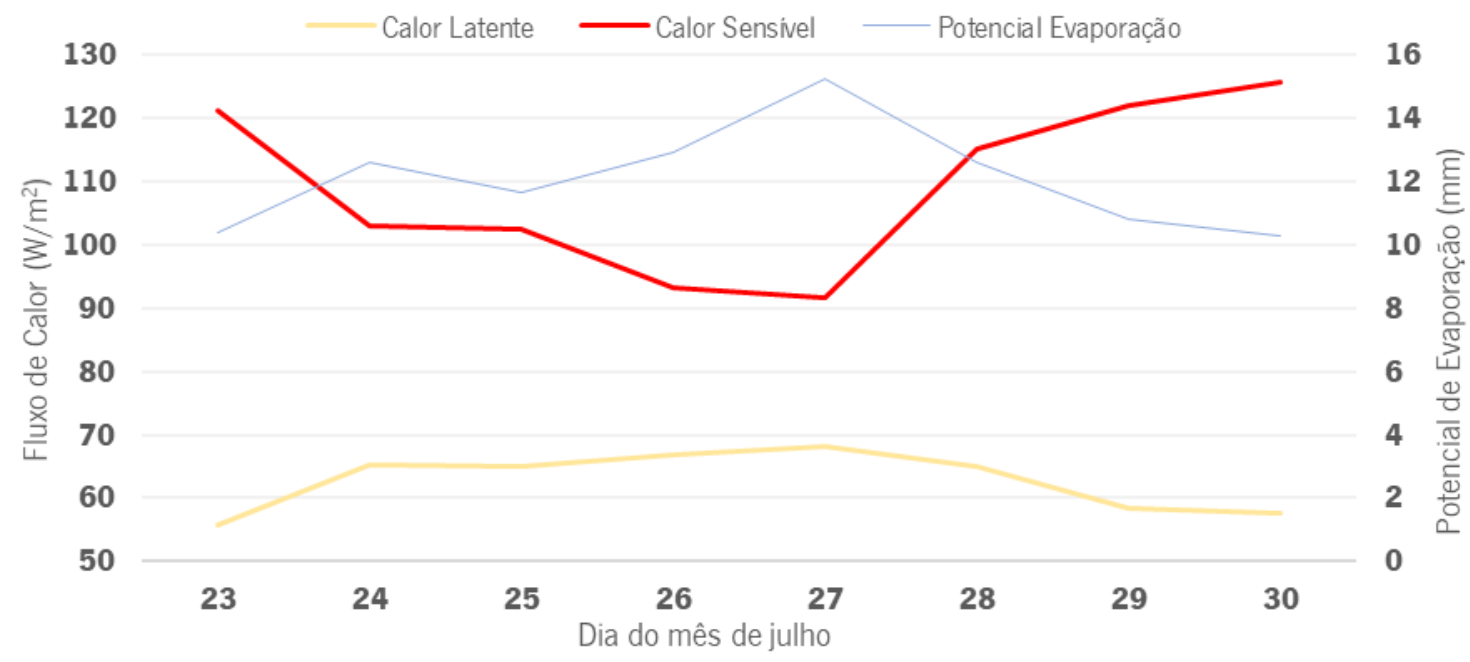

Figura 8 - Fluxos de calor sensível e de calor latente $\left(\mathrm{W} / \mathrm{m}^{2}\right)$ e potencial de evaporação $(\mathrm{mm})$ em Braga e Guimarães no decorrer da onda de calor.

Fonte: NOAA (2019).

A substituição dos fluxos de calor latente pelos de calor sensível contribui diretamente para o aquecimento do ar na atmosfera urbana inferior (Lopes, 2003; Zaitchik et al., 2006). Além disto, o aumento de temperatura nas áreas florestadas dos topos ao minimizar os contrastes térmicos com os centros urbanos, localizados no fundo de vale no caso de Braga e de Guimarães, enfraquece as diferenças de temperatura e de pressão que desencadeiam a circulação do ar - designadamente a brisa descendente de vertente (Geiger, 1990). Este fluxo de ar frio ao promover a renovação do ar e a mitigação da carga térmica nos centros urbanos desempenha um papel fundamental na regulação climática de todo o território. Em vista disso, deve ser dada especial atenção ao comportamento da vegetação (Ward et al., 2016), particularmente se considerarmos o cenário futuro de aumento das secas, decorrentes da redução e maior irregularidade da precipitação (IPCC, 2018) - constituindo o território português um do mais afetados (EEA, 2016a).

Nos locais com reduzido valor de NDVI - i.e. as áreas urbanas ou com solo exposto (visto os corpos de água apresentarem exígua dimensão nos municípios de Braga e de Guimarães) o dia com Ts mais elevada ocorre mais cedo do que nas áreas com vegetação (Tabela 3). Por 
conseguinte, os locais onde a vegetação está ausente parecem deter um comportamento térmico mais dependente da quantidade de radiação solar incidente.

Às 10:30 constata-se que as áreas sem vegetação exibem o máximo de Ts mais cedo do que as que têm vegetação, podendo esta situação estar relacionada com os campos agrícolas, nesta altura do ano geralmente lavrados e ainda sem vegetação. Notando que, neste horário o poder de explicação da correlação de Ts/NDVI é ligeiramente inferior ao verificado às 13:30. O solo húmido, como sucederia no início da onda de calor, detém elevada inércia térmica, pelo que aquece mais lentamente do que o solo seco, que detém menor inércia térmica (Curran, 1985). Com a perda de humidade, decorrente do calor extremo verificado nos dias em análise (vide Figura 6), o solo nu passa a atingir Ts muito elevadas logo a meio da manhã - assim, os valores mais reduzidos de Ts do início da onda de calor não se voltam a verificar.

Efetivamente, Fisher et al. (2007) "find a string of evidence suggesting that the dry soil conditions and ensuing soil moisture dynamics were the key in the sequence of events that led to the record-breaking summer of 2003" (p.5096). Assim, segundo os referidos autores, a fase mais quente da onda de calor de agosto de 2003 , não se deveu a uma anomalia no total de radiação solar, mas sim ao modo como esta foi transformada em fluxos de calor latente e de calor sensível - controlados em grande medida pelas condições de humidade do solo. A parca humidade do solo minimizou a evapotranspiração e o calor latente, sendo este fluxo compensado pelo calor sensível - que amplificou assim as anomalias da temperatura de superfície (Fisher et al., 2007).

\subsection{Padrão espacial}

A normalização de Ts média em cada horário do MODIS em função máximo e do mínimo da imagem uniformiza os valores, que passam a variar entre 0 e 1 . Por conseguinte, torna-se possível a classificação do ambiente térmico em função dos limiares propostos por Xiong et al. (2012), que facilitam a comparação direta do padrão térmico nos diferentes horários do MODIS, bem como entre os dois municípios (Figura 9). Assim, constata-se que o centro urbano de Braga constitui uma área crítica em todos os horários - i.e., uma 'área de calor acentuado' -, ao passo que Guimarães aparece relativamente mais fresco - i.e., 'área de 
calor moderado' ou 'área mediana'. Atendendo às similaridades das características fisiográficas e climáticas dos dois núcleos urbanos - que minimizam os fatores de variação climática local e regional - fica em evidência que as diferenças de Ts se deverão ao modelo territorial (i.e., a distribuição do edificado, das vias, da população e das atividades no território).
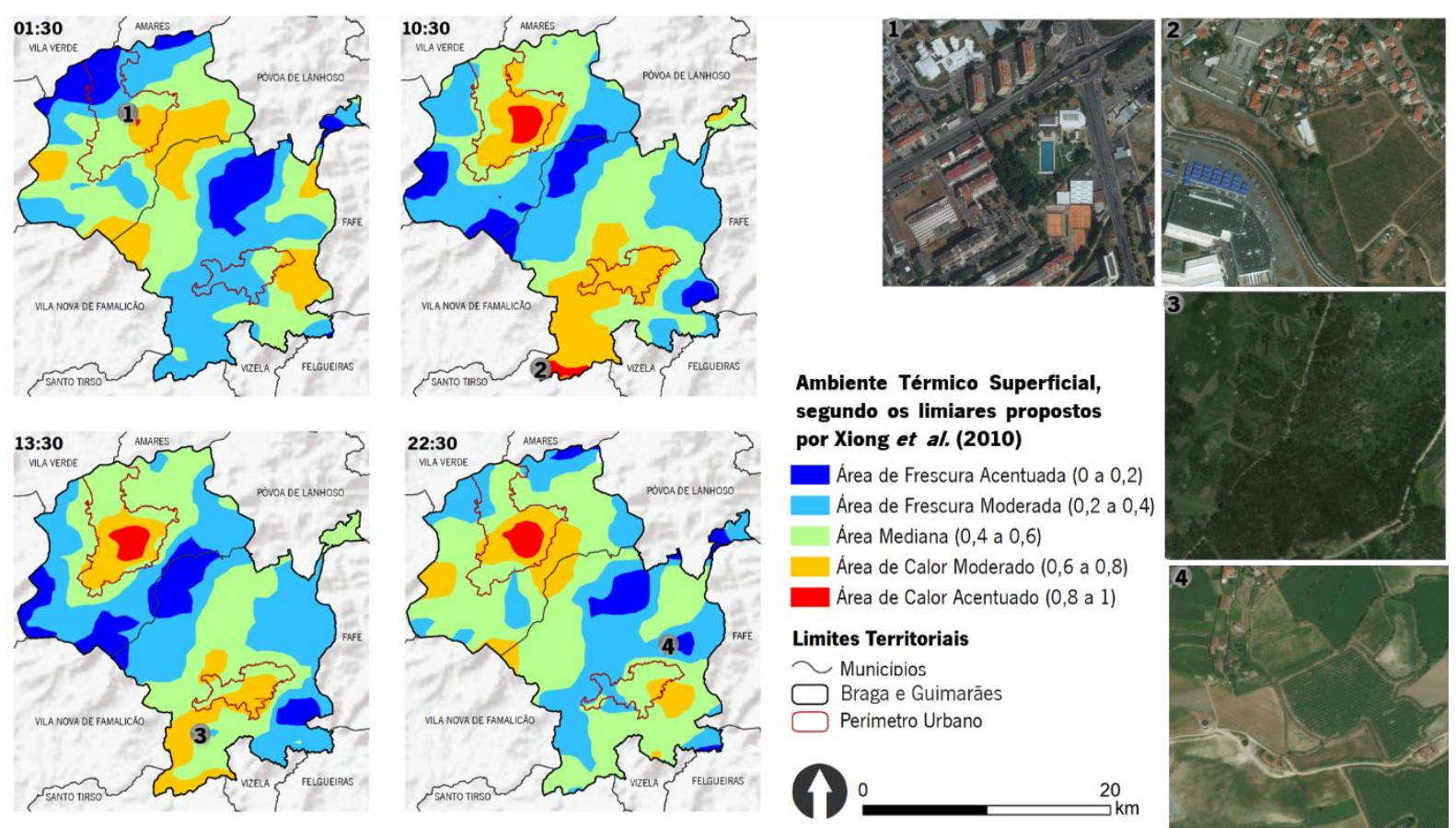

Exemplos da cobertura do solo: 1. área urbana em Braga; 2. urbanização difusa em Guimarães; 3. povoamento florestal em Guimarães; 4 campos agrícolas em Guimarães.

Figura 9 - Ambiente térmico superficial em Braga e Guimarães no decorrer da onda de calor, em função dos limiares propostos por Xiong et al. (2012)

No decurso da onda de calor, a morfologia urbana compacta, como sucede no interior do perímetro urbano bracarense, é claramente mais afetada pelo calor, como alerta a EEA (2012). Este sobreaquecimento advém das modificações nos fluxos de energia decorrentes da substituição de superfície permeáveis, com maior ou menor vegetação, por superfícies impermeáveis (Lopes, 2008), que ao favorecerem um leque diversificado de entradas de energia e ao bloquear as possíveis vias para a sua saída criam condições para se tornar no seu todo, ou em parte, uma ilha de calor (Monteiro, 1997).

A persistência das condições de calor no interior perímetro urbano bracarense durante a noite (Figura 9) revela-se especialmente preocupante, pois é neste período que as pessoas têm maior possibilidade de recuperação. Aliás, como advertem Dousset et al. (2007), "it is 
the lack of relief at night, rather than high daytime temperature, that constitute a human risk" (p.1). Para mais, Dousset et al. (2011) constataram que, no decurso da onda de calor de 1-13 de agosto de 2003 na região metropolitana de Paris, se verificou uma sobreposição entre a distribuição espacial das Ts mais altas e os rácios de mortalidade mais elevados no período noturno (entre as 20-22 UTC e as 0-3 UTC), não se observando esta mesma relação no período diurno.

Durante o dia, os topos densamente arborizados do Bom Jesus e da Penha constituem importantes ilhas de frescura, porém de madrugada é nos fundos de vale do rio Cávado, em Braga, e do Ave, em Guimarães que surgem as 'áreas de frescura acentuada' (Figura 9). Isto sucede porque, por um lado, a vegetação arbórea, por deter inércia térmica e capacidade calorífica elevadas (Curran, 1985), exibe uma maior resistência à variação de Ts - quer isto dizer, aquece e arrefece mais lentamente do que o solo nu ou o tecido urbano difuso que ocupam estes fundos de vale (Figura 9). Por outro lado, a sua individualização como ilhas de frescura acentuada à 01:30 poder-se-á ainda dever à acumulação do ar frio formado nos topos que, por ação da gravidade, vai escoando ao longo das vertentes (a denominada brisa descendente de vertente, de periodicidade diurna; Geiger, 1990), estimulando por isso a perdas de calor a partir da superfície. Importa ressalvar que a relação entre Ts, a temperatura do ar e a ventilação não foi objeto de estudo empírico neste território, porém a hipótese de que os movimentos do ar durante a noite condicionam a variação espacial de Ts foi igualmente avançada por outros autores (e.g., Voogt e Oke, 2003; Nichol, 2005). Lembrar que, o movimento catabático noturno do ar frio especialmente necessário para a renovação do ar e mitigação da carga térmica nos núcleos urbanos centrais de Braga e de Guimarães. Todavia, o avançar e/ou densificar da construção nas encostas do Bom Jesus e da Penha sobranceiras a Braga e Guimarães, respetivamente, mais do que implicações nas condições térmicas locais (i.e., domínio das condições de calor), ao promover o aumento da rugosidade perturba o escoamento do ar ao longo da vertente, enfraquecendo a regulação climática destes territórios.

Ao contrário do observado noutros estudos (e.g., Cheval et al., 2009; Mathew et al., 2018), designadamente para a cidade de Lisboa (Lopes, 2003), mesmo perante o calor extremo continuado como sucede no decorrer da onda de calor analisada, os núcleos urbanos centrais de Braga e de Guimarães não emergem de modo nítido como ilha de calor durante 
a madrugada (Figura 9). Efetivamente, é durante o dia (e, no horário de maior radiação solar) que a ilha de calor urbano das superfícies assume maior legibilidade, visto às 10:30 se estender de igual modo às áreas com solo nu (Figura 9).

\section{Nota Conclusiva}

As imagens de satélite possibilitam um conhecimento sem precedentes da superfície terrestre - nomeadamente em termos climáticos - que permite destrinçar as especificidades de cada território, suportando ou refutando conclusões enunciadas a escalas mais amplas. A análise diacrónica de Ts coloca em evidência que os efeitos da onda de calor nos municípios de Braga e de Guimarães são assimétricos do ponto de vista temporal (i.e., nos diferentes horários do MODIS), e espacial, decorrente da ocupação do solo, ou de outros fatores, como a posição topográfica.

As imagens MODIS ao facultarem uma cartografia detalhada das áreas com maior carga térmica, bem como dos ciclos de aquecimento e de arrefecimento do território, revela-se um importante input para os Planos Municipais de Ordenamento do Território designadamente para o Plano Diretor Municipal (PDM) -, e muito em particular para os Planos Municipais de Emergência. Dessarte, auxilia na definição de políticas urbanas indutoras de um território ambiental e socialmente resiliente.

Relativamente ao PDM, que visa entre outros aspetos a definição da estrutura ecológica, sustenta a estratégia ao nível dos espaços verdes municipais, nomeadamente a opção por parques arborizados, que fornecem sombra durante o dia e promovem o arrefecimento evaporativo, ou relvados, com elevado sky view factor, que permitem o rápido arrefecimento com o cessar da radiação, em função das atividades dominantes no espaço envolvente (i.e., comercial e serviços no primeiro caso e estritamente residencial no segundo).

Nos Planos Municipais de Emergência a identificação dos locais onde sistematicamente se verifica uma carga térmica muito elevada suporta a definição de áreas de intervenção prioritária, quer para a implementação de medidas de prevenção (e.g., promoção da arborização, aumento do albedo das coberturas, melhoria do isolamento do edificado, 
colocação de aparelhos de ar condicionado), quer de resposta dos meios de socorro em dias críticos. Para uma cartografia pormenorizada da vulnerabilidade ao calor extremo, o tratamento de Ts ao nível da subsecção estatística permite fazer a relação entre os locais com maior exposição (i.e., com elevada carga térmica) e as variáveis sociodemográficas, que determinam a sensibilidade da população, bem como as variáveis económicas, vitais na determinação capacidade de adaptação. Efetivamente, o conhecimento destas geografias é fundamental para a cabal compreensão dos impactes do calor extremo no território e na população, bem como para a eficácia das ações de resposta (IPCC, 2007; Pinheiro e Laranjeira, 2016). A título de exemplo, Dousset et al. (2011) consideram que a análise integrada de Ts com as variáveis supramencionadas se revela útil na delineação de medidas preventivas para reduzir atividades extenuantes em áreas industriais, onde Ts atinge valores muito elevados durante o dia, bem como prestar assistência à população idosa, onde Ts se mantém elevada durante a noite.

A cartografia da exposição, sensibilidade e capacidade de adaptação constitui informação particularmente vital aquando da elaboração de planos de ação para o calor extremo, cada vez mais necessários no atual contexto climático. Estes planos devem ser pensados ao nível: (i) das medidas de prevenção (e.g., campanhas de sensibilização acerca dos efeitos do calor extremo na saúde humana, identificação da população mais idosa ou doente, sempre mais sensível; determinação de locais com atividade laboral fisicamente exigente); (ii) do sistema de alerta (i.e., monitorização em tempo real pelos serviços meteorológicos); e, (iii) dos meios de resposta.

\section{Agradecimentos}

Este trabalho foi suportado pela Fundação da Ciência e Tecnologia (FCT), através da Bolsa de Doutoramento SFRH/BD/111263/2015.

\section{Referências}

APA (2020). Adaptação em Portugal - Escala Local. Disponível em: https://apambiente.pt/index. php?ref=16\&subref=81\&sub2ref=118\&sub3ref=395. 
Bazaz, A., Bertoldi, P., Buckeridge, M., Cartwright, A., de Coninck, H., Engelbrecht, F., ... \& Lwasa, S. (2018). Summary for urban policymakers: What the IPCC Special Report on global warming of $1.5^{\circ} \mathrm{C}$ means for cities. Bengaluru: Indian Institute for Human Settlements.

Cheval, S., Dumitrescu, A., \& Bell, A. (2009). The urban heat island of Bucharest during the extreme high temperatures of July 2007. Theoretical and Applied Climatology, 97(3-4), 391-401.

Curran, P. (1985). Principles of remote sensing. London: Longman Group Limited.

Daveau, S. (1985). Mapas Climáticos de Portugal Nevoeiros e Nebulosidade Contrastes Térmicos. Lisboa: Memórias do Centro de Estudo Geográficos.

Dousset, B., Gourmelon, F., \& Mauri, E. (2007). Application of satellite Remote Sensing for Urban Risk Analysis: a case study of the 2003 extreme heat wave in Paris. Urban Remote Sensing Joint Event, IEEE-2007, 1-5.

Dousset, B., Gourmelon, F., Laaidi, K., Zeghnoun, A., Giraudet, E., Bretin, P., ... \& Vandentorren, S. (2011). Satellite monitoring of summer heat waves in the Paris metropolitan area. International Journal of Climatology, 31(2), 313-323.

Depietri, Y., Welle, T., \& Renaud, F. G. (2013). Social vulnerability assessment of the Cologne urban area (Germany) to heat waves: links to ecosystem services. International Journal of Disaster Risk Reduction, 6, 98117.

EEA (2012). Climate change, impacts and vulnerability in Europe 2012. An indicator-based report. Copenhagen: European Environment Agency.

EEA (2016a). Climate change, impacts and vulnerability in Europe 2016. An indicator-based report. Copenhagen: European Environment Agency.

EEA (2016b). Extreme temperatures and health. Copenhagen: European Environment Agency.

EEA (2017). Preparing Europe's cities for climate change impacts. Disponível em: https://www.eea.europa.eu/articles/preparing-europe2019s-cities-for-climate.

Fischer, E., Seneviratne, S., Vidale, P., Lüthi, D., \& Schär, C. (2007). Soil moisture-atmosphere interactions during the 2003 European summer heat wave. Journal of Climate, 20(20), 5081-5099.

Geiger, R. (1990). Manual de Microclimatologia. O clima da camada do ar junto ao solo. Lisboa: Fundação Calouste Gulbenkian.

IPCC (2007). Climate Change 2007: Impacts, Adaptation Vulnerability. New York: Cambridge University Press.

IPCC (2018). Global warming of $1.5^{\circ} \mathrm{C}$ - Summary for Policymakers. Switzerland: Intergovernmental Panel on Climate Change.

IPMA (2010). Boletim Climatológico Mensal - julho 2010. Disponível em: http://www.ipma.pt/resources.www/docs/im.publicacoes/edicoes.online/20100805/vyJoENHeCqVoSirCTGW $\mathrm{m} / \mathrm{cli} 2010070120100731 \mathrm{pcl} \mathrm{mm}$ co pt.pdf.

IPMA (2019). Normal Climatológica de Braga. Disponível em: http://www.ipma.pt/pt/oclima/normais.clima/004/.

IPMA (2020). Boletim Climatológico Mensal - julho 2020. Disponível em: http://www.ipma.pt/resources.www/docs/im.publicacoes/edicoes.online/20200806/QjVTABosEPrZtOOiteHA/ cli 2020070120200731 pcl mm co pt.pdf.

Klock, L., Zwart, S., Verhagen, H., \& Mauri, E. (2012). The surface heat island of Rotterdam and its relationship with urban surface characteristics. Resources, Conservation and Recycling, 64, 23-29.

Lopes, A. (2003). Modificações no clima de Lisboa como consequência do crescimento urbano. vento, ilha de calor de superfície e balanço energético. Tese de Doutoramento em Geografia, Universidade de Lisboa, 375pp.

Lopes, A. (2008). O sobreaquecimento das cidades: causas e medidas para a mitigação da ilha de calor de Lisboa. Territorium, 15, 39-52. 
Mathew, A., Khandelwal, S., Kaul, N., \& Chauhan, S. (2018). Analyzing the diurnal variations of land surface temperatures for surface urban heat island studies: Is time of observation of remote sensing data important?. Sustainable Cities and Society, 40, 194-213.

Monteiro, A. (1997). O Clima Urbano do Porto - Contribuição para a definição das estratégias de planeamento e ordenamento do território. Lisboa: Fundação Calouste Gulbenkian.

Nichol, J. (2005). Remote sensing of urban heat islands by day and night. Photogrammetric Engineering \& Remote Sensing, 71(5), 613-621.

NOOA (2019). Climate Forecast System Reanalysis dataset - NOAA NWS National Centers for Environmental Prediction (NCEP). Disponível em: https://app.climateengine.org/.

Pinheiro, C., \& Laranjeira, M. (2013). Análise do ambiente térmico e das condições de ventilação para a definição das funções climáticas na área urbana de Guimarães. GOT - Revista de Geografia e Ordenamento do Território, 4, 249-272.

Pinheiro, C., \& Laranjeira, M. (2016). Análise Espacial da Vulnerabilidade da População de Braga aos Eventos de Calor Extremo. In R. Marín, F. Sarría, F. Serrato, D. Muñoz (Eds.), Actas do XV Coloquio Ibérico de Geografía Retos y tendencias de la Geografía Ibérica, Universidade de Murcia, pp.307-315.

Pinheiro, C., Laranjeira, M., \& Bandeira, M. (2016a). Mudança no Ambiente Térmico em Guimarães (19842014): o impacte da urbanização difusa. In J. Correia, M. Bandeira (Coords.), Os Espaços da Morfologia Urbana' - Atas da 5ạ Conferência Internacional da Rede Lusófona de Morfologia Urbana, PNUM 2016, pp.409-415.

Pinheiro, C., Laranjeira, M., \& Bandeira, M. (2016b). Análise por deteção remota da variação espaciotemporal da temperatura de superfície e sua relação com a urbanização em Braga (1984-2014). In A. Vieira, A. Gonçalves, F. Costa, L. Cunha, A. Troleis (Coords.), Atas do II Encontro Luso-Afro-Americano de Geografia Física e Ambiente - "Desafios Para Afirmar a Lusofonia na Geografia Física e Ambiente, Universidade do Minho, pp. $1345-1354$.

PNPOT (2018). PNPOT - Alteração: Estratégia e Modelo Territorial. Lisboa: República Portuguesa.

Portal do Clima (2015). ESTAÇÕES - Estação Meteorológica de Braga. Disponível em: http://portaldoclima.pt/pt/\#.

Retalis, A., Paronis, D., Lagouvardos, K., \& Kotroni, V. (2010). The heat wave of June 2007 in Athens, GreecePart 1: Study of satellite derived land surface temperature. Atmospheric Research, 98, 458-467.

Retief, S., Willers, C., \& Wheeler, M. (2003). Prediction of thermal crossover based on imaging measurements over the diurnal cycle. In N. Faust \& W. Roper (Eds.), Geo-Spatial and Temporal Image and Data Exploitation III (Volume 5097), International Society for Optics and Photonics, pp. 58-70.

Ribeiro, O. (1994). Opúsculos Geográficos. V Volume - Temas Urbanos. Lisboa: Fundação Calouste Gulbenkian.

Sun, R., Lü, Y., Yang, X., \& Chen, L. (2019). Understanding the variability of urban heat islands from local background climate and urbanization. Journal of Cleaner Production, 208, 743-752.

Voogt, J., \& Oke, T. (2003). Thermal remote sensing of urban climates. Remote Sensing of Environment, 86(3), 370-384.

Xiong, Y., Huang, S., Chen, F., Ye, H., Wang, C., \& Zhu, C. (2012). The impacts of rapid urbanization on the thermal environment: A remote sensing study of Guangzhou, South China. Remote Sensing, 4(7), 2033-2056.

Zaitchik, B., Macalady, A., Bonneau, L., \& Smith, R. (2006). Europe's 2003 heat wave: a satellite view of impacts and land-atmosphere feedbacks. International Journal of Climatology, 26(6), 743-769. 